\title{
Caries removal by Er,Cr:YSGG laser and Air-rotor handpiece comparison in primary teeth treatment: an in vivo study
}

\author{
Smriti Johar, Mridula Goswami, Gyanendra Kumar, Jatinder Kaur Dhillon \\ Pedodontics \& Preventive Dentistry, Maulana Azad Institute of Dental Sciences, New Delhi
}

\begin{abstract}
Aim: The aim of this study was to evaluate and compare caries removal by Er,Cr:YSGG Laser and conventional method using Air-rotor handpiece in primary teeth.

Materials and Methods: 25 children with at least two class I carious lesions on primary teeth with Diagnodent readings not differing more than \pm 10 for both teeth were included in the study. All 50 teeth in the study received treatment by the same operator. Time taken for caries removal was recorded using a timer. Pain assessment was done using Wong Baker Modified Faces Pain Rating Scale and Visual Analog Scale before and after the procedure. After caries removal, caries detection dye was applied to the prepared cavity to check the efficacy of the procedure. In addition, after completion of treatment, each child was asked to indicate which method of caries removal, Er,Cr:YSGG Laser or Air-rotor handpiece, was more comfortable.

Results: The difference between the mean values for post-procedural Wong Baker Faces Pain Rating Scale scores and Visual Analog Scale scores in Group A and Group B were compared, which showed that children experienced less pain during the caries removal procedure with Er,Cr:YSGG Laser than with Air-rotor handpiece. Time taken for caries removal procedure was more in Group A than in Group B. It was seen that in both the groups caries detection dye was completely removed and both the procedures were equally efficacious for caries removal. Children indicated caries removal procedure with Laser to be more comfortable.

Conclusion: Within the parameters and limitations of the present study, it is suggested that Er,Cr:YSGG Laser seems to be an acceptable tool for caries removal in primary teeth. Children found caries removal with Er,Cr:YSGG Laser to be more comfortable even though time taken was more than the conventional method using Air-rotor handpiece.
\end{abstract}

Key words: Er,Cr:YSGG Laser • Air-rotor handpiece $\cdot$ Pain assessment

\section{Introduction}

Air-rotor handpieces and burs are among the most frequently used mechanical devices for caries removal as it is cost-effective, less time consuming and easy to use. However, their use has several disadvantages such as high-pitched noise and bone-conducted vibrations that often make patients feel uncomfortable. The noise and vibrations of a conventional handpiece may be terrifying to children and lead to increase in dental anxiety. ${ }^{1)}$ This may also lead to unwanted head and body movements

\section{Addressee for Correspondence:}

Dr Smriti Johar

Postgraduate Student

Pedodontics \& Preventive Dentistry

Maulana Azad Institute of Dental Sciences New Delhi

Phone: +919899282815

E-mail: drsmritijohar@gmail.com due to anxiety. To overcome these advantages various techniques are available such as air-abrasion, air-polishing, ultrasonication, sono-abrasion, chemo-mechanical methods and Lasers. ${ }^{2)}$

Erbium Laser have been introduced for various hard and soft tissue applications including caries removal. The Er,Cr:YSGG Laser has an emission wavelength of 2780 $\mathrm{nm}$, and is strongly absorbed by water and hydroxyapatite. This energy when absorbed by water is used to cause rapid vaporization and to create microexplosions in hard tissue. Ideally, the remaining dental tissue beneath should not be affected by the ablation, thereby allowing precise control and minimal damage to the surrounding tissue. ${ }^{3)}$ The Erbium Laser's shallow depth of tissue penetration, high affinity with water and lack of thermal dam-

Received date: September 25, 2018

Accepted date: January 18, 2019 
age make it an ideal Laser for paediatric dentistry. ${ }^{4}$ )

The aim of this in vivo study was to compare the caries removal using Er,Cr:YSGG Laser and Air-rotor handpiece in primary teeth.

\section{Materials and methods}

The present study was done after obtaining prior approval from the ethical committee of the institution. Study sample comprised of 50 teeth in 25 children aged 6-10 years, who visited the outpatient department of Pedodontics and Preventive Dentistry, at Maulana Azad Institute of Dental Sciences, New Delhi. The sample size was estimated based on the previous literature findings and by consulting a biostatistician. Twenty five children with atleast two class I carious lesions on primary teeth were included in the study. In each child one tooth was treated with Er,Cr:YSGG Laser (Waterlase, Biolase Tech Inc, San Clemente,CA) and the other with Air-rotor handpiece (Pana Max AIR, NSK,Japan), making total study sample as 50 teeth (25 children).

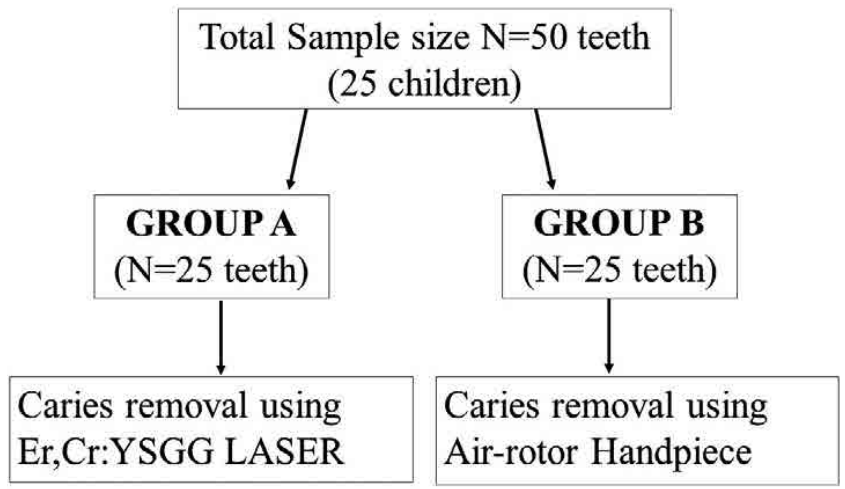

Written Informed content was obtained from the parent/ guardian accompanying the child. The teeth were selected for the procedure if the inclusion and exclusion criteria were fulfilled. Diagnodent (Diagnodent, Kavo, Joinville, SC, Brazil) readings were taken for each tooth. Children with at least two class I cavities, with Diagno- dent readings not differing more than \pm 10 for both teeth, were included in the study. All 50 teeth in the study received treatment by the same operator. Two teeth in each child were treated. One tooth was prepared using the Er,Cr:YSGG Laser (Group A), and the other tooth was prepared using a conventional high-speed Air-rotor handpiece (Group B). Both procedures were performed on the same day by a single operator. The decision as to which tooth should be prepared by Er,Cr:YSGG Laser or Air-rotor handpiece was selected randomly by means of flipping a coin. The sequence of caries removal with Er,Cr:YSGG Laser and Air-rotor handpiece was alternated from child to child and isolation was achieved with the help of rubber dam.

In Group A (Er,Cr:YSGG Laser) protective goggles specific for the wavelength used were worn to protect the eyes of both the operator and the child. The Laser beam was delivered through an articulated arm with a $90^{\circ}$ handpiece and a $600 \mu$ Laser tip in non-contact mode with water-cooling. Removal of caries was done with Laser irradiation using Er,Cr:YSGG Laser with the following parameters - Power- 6 watt, frequency- 25 hertz, water:air ratio-60:40, Fluence-55.5 J/ $\mathrm{cm}^{2}$, Pulse duration- 140 microseconds. Time taken for caries removal was recorded using a timer beginning from the first Laser pulse until the last pulse.

In Group B (Air-rotor handpiece) caries were removed using Air-rotor handpiece (400000 rpm) with water spray and no. 2 round carbide bur and time taken for caries removal was recorded using a timer initiated with the first contact between the bur and tooth until the last contact.

After caries removal caries detection dye (Caries Detector, Kuraray, Noritake Dental Inc, Japan) was applied to the prepared cavity with the help of applicator tip and left for 10 seconds. The cavity was subsequently rinsed with water for 10 seconds and then air-dried using threeway syringe and the cavity was then checked for any residual caries detection dye.

Before and after the procedure, each child was asked about his/her perception of pain using Wong Baker Modified Faces Pain Rating Scale (Figure 1). This Fa-

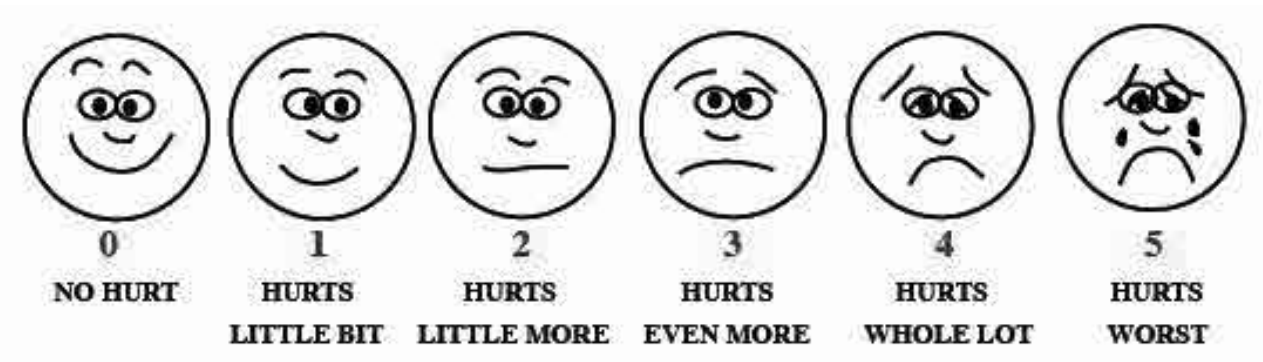

Figure 1: Wong Baker Faces Pain Rating Scale 


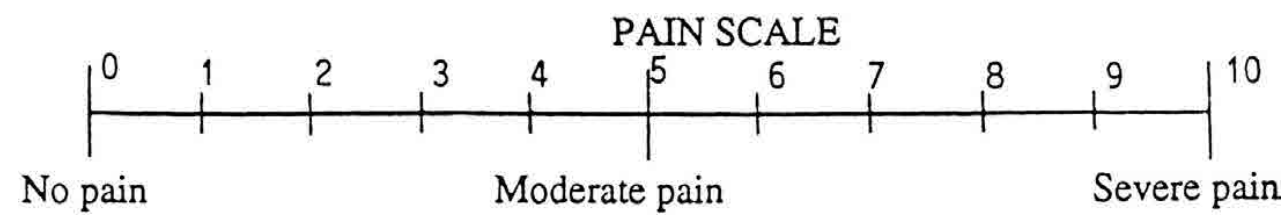

Figure 2: Visual Analog Scale

cial Image Scale comprises a row of six faces ranging from very happy to very unhappy. Score of WBFPRS was recorded by the operator. Visual Analog Scale (Figure 2) which is a linear scale ranging between the values 0 (no pain) to 10 (severe pain), was also used before and after the procedure and the scores were recorded. After complete removal of caries the tooth was restored with cermet (Hi Dense, Shofu Inc, Japan). In addition, following completion of treatment, each child was asked to indicate which method of caries removal, Er,Cr:YSGG Laser or Air-rotor handpiece, was more comfortable, and which type of procedure they would prefer in the future. After complete removal of caries the tooth was restored with cermet.

Data analysis was performed using Statistical Package for the Social Sciences-21 (SPSS-21). The data was analyzed using Mann-Whitney Test and Wilcoxon Signed Ranks Test and p-values $<0.05$ were considered statistically significant.

\section{Results}

\section{Group A (Er,Cr:YSGG Laser)}

In Group A (Er,Cr:YSGG Laser) mean value for pre-procedural and post-procedural Wong Baker Faces Pain Rating Scale (WBFPRS) score were $0.40 \pm 1.12$, and $0.577 \pm$ 1.013 respectively. The difference was statistically significant ( $p=0.001)$ (Table 1). It showed that children experienced more pain during the treatment.

Table 1: Mean and standard deviation of pre-procedural and post-procedural Wong Baker Faces Pain Rating Scale scores in Group A.

\begin{tabular}{lccc}
\hline & Mean \pm SD & Z & significance \\
\hline $\begin{array}{l}\text { Pre-procedural } \\
\text { WBFPRS score }\end{array}$ & $0.40 \pm 1.0 .577$ & & \\
\cline { 1 - 2 } $\begin{array}{l}\text { Post- procedural } \\
\text { WBFPRS score }\end{array}$ & $1.12 \pm 1.013$ & & 0.001 \\
\hline
\end{tabular}

In Group A (Er,Cr:YSGG Laser) mean value for pre-procedural and post-procedural Visual Analog Scale (VAS) score were $0.48 \pm 0.770$ and $1.76 \pm 1.508$ respectively.
The difference was statistically significant $(\mathrm{p}=0.001)$ (Table 2). This suggests that more number of children felt pain during the procedure.

Table 2: Mean and standard deviation of pre-procedural and post-procedural Visual Analog Scale scores in Group A.

\begin{tabular}{lccc}
\hline & Mean \pm SD & Z & significance \\
\cline { 1 - 2 } $\begin{array}{l}\text { Pre-procedural } \\
\text { VAS score }\end{array}$ & $0.48 \pm 0.770$ & & \\
\cline { 1 - 2 } $\begin{array}{l}\text { Post- procedural } \\
\text { VAS score }\end{array}$ & $1.76 \pm 1.508$ & & 0.001 \\
\hline
\end{tabular}

Time taken for caries removal in Group A using Er,Cr:YSGG Laser ranged from 147 seconds to 236 seconds with a mean of $189.64 \pm 23.18$ seconds

\section{Group B (Air-rotor handpiece)}

Mean values for pre-procedural and post-procedural pain assessment in Group B (Air-rotor handpiece) using Wong Baker Faces Pain Rating Scale (WBFPRS) were $0.64 \pm$ 0.810 and $1.92 \pm 0.954$ respectively. The difference was statistically significant $(\mathrm{p}=0.001)$ (Table 3). It showed that the children experienced more pain during the procedure.

Table 3: Mean and standard deviation of pre-procedural and post-procedural Wong Baker Faces Pain Rating Scale scores in Group B.

\begin{tabular}{lccc}
\hline & Mean \pm SD & Z & significance \\
\cline { 1 - 2 } $\begin{array}{l}\text { Pre-procedural } \\
\text { WBFPRS score }\end{array}$ & $0.64 \pm 0.810$ & & \\
\cline { 1 - 2 } $\begin{array}{l}\text { Post- procedural } \\
\text { WBFPRS score }\end{array}$ & $1.92 \pm 0.954$ & & 0.001 \\
\hline
\end{tabular}

In Group B (Air-rotor handpiece) mean values for pre-procedural and post-procedural pain assessment using Visual Analog Scale (VAS) were $0.92 \pm 1.32$ and 2.88 \pm 1.481 respectively. The difference was statistically significant $(p=0.001)$ (Table 4). It showed that the children experienced more pain during the procedure. 
Table 4: Mean and standard deviation of pre-procedural and post-procedural Visual Analog Scale scores in Group B.

\begin{tabular}{|c|c|c|c|}
\hline & Mean \pm SD & $\mathrm{Z}$ & significance \\
\hline $\begin{array}{l}\text { Pre-procedural } \\
\text { VAS score }\end{array}$ & $0.92 \pm 1.32$ & \multirow{2}{*}{-4.097} & \multirow{2}{*}{0.001} \\
\hline $\begin{array}{l}\text { Post- procedural } \\
\text { VAS score }\end{array}$ & $2.88 \pm 1.481$ & & \\
\hline
\end{tabular}

Time taken for caries removal in Group B (Air-rotor handpiece) using Air-Rotor handpiece ranged from 7 seconds to 30 seconds with a mean of $13.60 \pm 5.39$ seconds.

\section{Comparison between Group A (Er,Cr:YSGG La- ser) and Group B (Air-rotor handpiece)}

The mean values for post-procedural Wong Baker Faces Pain Rating Scale scores (WBFPRS) in Group A (Er,Cr:YSGG Laser) and Group B (Air-rotor handpiece) were 1.12 \pm 1.013 and $1.92 \pm 0.954$ respectively. The difference was statistically significant ( $\mathrm{p}=0.01$ ) (Table 5). It showed that children experienced less pain during the caries removal procedure with Er,Cr:YSGG Laser than with Air-rotor handpiece.

Table 5: Mean and standard deviation of post procedural Wong Baker Faces Pain Rating Scale scores in Group A and Group B

\begin{tabular}{lcccc}
\hline & Mean \pm SD & $\begin{array}{c}\text { Mann- } \\
\text { Whitney }\end{array}$ & $\begin{array}{c}\text { Wilcoxon } \\
\text { W }\end{array}$ & $\begin{array}{c}\text { Signifi- } \\
\text { cance }\end{array}$ \\
\cline { 1 - 1 } Group A & $1.12 \pm 1.013$ & 186.500 & 511.500 & 0.01 \\
\hline Group B & $1.92 \pm 0.954$ & & & \\
\hline
\end{tabular}

The mean values for post-procedural Visual Analog Scale (VAS) scores in Group A (Er,Cr:YSGG Laser) and Group B (Air-rotor handpiece) were $1.76 \pm 1.508$ and $2.88 \pm 1.481$ respectively. The difference was statistically significant ( $\mathrm{p}$ $=0.01$ ) (Table 6). It showed that children experienced less pain during the caries removal procedure with Er,Cr:YSGG Laser than with Air-rotor handpiece.

Table 6: Mean and standard deviation of postprocedural Visual Analog Scale scores in Group A and Group B

\begin{tabular}{lcccc}
\hline & Mean \pm SD & $\begin{array}{c}\text { Mann } \\
\text { Whitney }\end{array}$ & $\begin{array}{c}\text { Wilcoxon } \\
\text { W }\end{array}$ & $\begin{array}{c}\text { Signifi- } \\
\text { cance }\end{array}$ \\
\cline { 1 - 2 } Group A & $1.76 \pm 1.508$ & \multirow{2}{*}{179.000} & 504.000 & 0.010 \\
\cline { 1 - 2 } Group B & $2.88 \pm 1.481$ & & & \\
\hline
\end{tabular}

The mean values for time taken for caries removal procedure in Group A (Er,Cr:YSGG Laser) and Group B
(Air-rotor handpiece) were 189.64 \pm 23.18 seconds and $13.60 \pm 5.39$ seconds respectively. The difference between the mean values was compared using Mann-Whitney Test and it was statistically significant $(\mathrm{p}=0.001)$ (Table 7). It showed that time taken for caries removal procedure was more in Group A than in Group B.

Table 7: Mean and standard deviation of time taken for caries removal in Group A and Group B

\begin{tabular}{llccc}
\hline & Mean \pm SD & $\begin{array}{c}\text { Mann } \\
\text { Whitney }\end{array}$ & $\begin{array}{c}\text { Wilcoxon } \\
\text { W }\end{array}$ & $\begin{array}{c}\text { signifi- } \\
\text { cance }\end{array}$ \\
\cline { 1 - 2 } Group A & $189.64 \pm 23.18$ & 0.000 & 325.000 & .0001 \\
\cline { 1 - 2 } Group B & $13.60 \pm 5.39$ & & & \\
\hline
\end{tabular}

Efficacy of the procedure was assessed using caries detection dye depending on whether it was partially removed or completely removed. It was seen that in both the groups caries detection dye was completely removed and both the procedures were equally efficacious for caries removal.

After the completion of procedure, children were asked which method of cavity preparation (Laser or Airrotor handpiece) felt more comfortable to them and the response was noted. As per the results, 20(80\%) children found the procedure of caries removal with Laser to be more comfortable.

\section{Discussion}

The most commonly used method for the treatment of dental caries is mechanical removal of carious lesion using Air-rotor handpiece and bur as it is cost-effective, less time consuming and easy to use. However, this method has several disadvantages such as high-pitched noise and bone-conducted vibrations that often make patients feel uncomfortable. The noise and vibrations of a conventional handpiece may be terrifying to children and lead to increase in dental anxiety and unwanted head and body movements. ${ }^{5)}$ The non-contact mode of Erbium Lasers with hard tissue eliminates the vibratory effects of the conventional high-speed handpiece allowing tooth preparations to be comfortable and less anxiety provoking for children and adolescents. ${ }^{6}$ This study was planned to evaluate and compare the caries removal using Er,Cr:YSGG Laser and Air-rotor handpiece in primary teeth.

Results of the present study indicate that the children found caries removal with Er,Cr:YSGG Laser to be more comfortable than with Air-rotor handpiece. 80\% of the children preferred caries removal with Er,Cr:YSGG Laser. This finding is similar to the findings of Eren $\mathrm{F}$ et al. ${ }^{7)}$ In their study children showed a significant preference for Laser ablation as a method of cavity preparation. Of the children, 95\% felt more comfortable with Laser therapy, and 90\% would choose the Laser as the cavity prepa- 
ration tool at their next dental visit.

Diagnodent was used in this study to ensure that the caries depth in both the groups should not differ more than \pm 10 Diagnodent readings. This device was preferred over other methods of caries detection as it is non-invasive and does not cause any damage to the integrity of the enamel surface promoting conditions for caries development. ${ }^{8)}$ Diagnodent has shown high sensitivity (100\%) and acceptable specificity (44\%) in detection of occlusal caries when compared to visual and radiographic methods in studies conducted by Rocha et al ${ }^{9)}$ and Bengston et al. ${ }^{10)}$ Caries detection using Diagnodent is based on the principle that when tooth surface is irradiated with $655 \mathrm{~nm}$ wavelength Diode Laser, light is absorbed by metabolites of intraoral bacteria and these metabolites emit a red fluorescence. This fluorescence reflected by the dental surface is indicated as a number between 0 and 99 on the screen of the device. Higher reading indicates farther spread of decay. ${ }^{11)}$ Therefore Laser fluorescence provides a quantitative and non-invasive method for the diagnosis of dental caries. ${ }^{12}$ The use of Diagnodent to evaluate primary caries in permanent teeth has been shown to have high sensitivity which makes this device suitable for diagnosis. ${ }^{13}$ )

In this study, Wong Baker Faces Pain Rating Scale was used to evaluate and compare the pain perception during caries removal with both the methods as it is a valid and reliable tool for pediatric patients. ${ }^{14)}$ This scale was developed by Donna Wong and Connie Baker. ${ }^{15)}$ The scale shows a series of faces ranging from a happy face at ' 0 ' which represents "no hurt" to a crying face at ' 5 ' which represents "hurts worst." Based on the faces and descriptions, the patient chooses the face that best describes their level of pain. It is easy to administer and rate, does not take too much time to complete and can be used with children and adolescents. Khatri A and Kalra N in 2010 assessed the pain in 180 patients aged 3-14 year-old and also compared pain measurement techniques, i.e., Visual Analog Scale and Wong-Baker Faces Pain Rating Scale. Interaction between sex and age was not significant both for Visual Analog Scale and for Wong-Baker Faces Pain Rating Scale. However, they concluded that Wong-Baker Faces Pain Rating Scale was more sensitive as compared to Visual Analog Scale. ${ }^{67)}$ Boj J et al (2005) used Wong Baker Faces Pain Rating Scale to evaluate the pain perception in pediatric dental patients with the use of an Er, Cr: YSSG Laser for cavity preparations and oral surgical procedures. They suggested that Wong Baker Faces Pain Rating Scale is easy to administer and rate, does not take too much time to complete and can be used in children and adolescents as faces are not ambiguous and is easy to understand. ${ }^{16}$ Before and after every procedure children were asked to point at the face that best represented their level of pain on Wong Baker Faces Pain Rating Scale.
In addition to Wong Baker Faces Pain Rating Scale, Visual Analog Scale was also used for pain assessment in the present study as it is a reliable tool for children above five years of age. ${ }^{17)}$ The Visual Analog Scale (VAS) is a psychometric response scale. It is a measurement instrument for subjective characteristics or attitudes that cannot be directly measured. It is a linear scale ranging between the values 0 (no pain) to 10 (severe pain). It is simple to use and correlates well with recognized measures of dental anxiety. ${ }^{19)}$ Paul SM et al (1999) tested the hypothesis that the Visual Analog Scale (VAS) is a linear pain measurement. They studied 52 postoperative patients and measured their pain intensity using VAS. It was seen that the VAS has properties consistent with a linear scale, at least for patients with mild-to-moderate pain, and a change in the Visual Analog Scale score represents a relative change in the magnitude of pain sensation. They concluded that use of the Visual Analog Scale in comparative analgesic trials can meaningfully quantify differences in potency and efficacy. ${ }^{70)}$ Rathnam A, Madan N, Madan N (2000) used Visual Analog Scale of faces to evaluate the pain perception of children and correlated it with various environmental factors and parental understanding of the pain felt by their children. They also correlated the pain perception of the patient with his/her behaviour in the dental set up and suggested that Visual Analog Scale can be used as a reliable tool for children above five years of age. ${ }^{73)}$ Before and after every procedure children were asked to point at the value that best correlated with their level of pain on Wong Baker Faces Pain Rating Scale.

In the present study, pain assessment done through WBFPRS and VAS showed that children felt more pain after the procedure in both the groups Pain assessment with both the scales showed that children experienced less pain during the caries removal procedure with Er,Cr:YSGG Laser than with Air-rotor handpiece.

Matsumoto K, Hossain M, Hossain MM, Kawano H, Kimura Y (2002) used Er,Cr:YSGG Laser to prepare class I - V cavities and evaluated the clinical outcome. No adverse reaction was seen in any of the cases. They suggested that this Laser is an efficient, effective, and safe device for caries removal and cavity preparation. They also found that the patient acceptance rate for Er,Cr:YSGG Laser was excellent. ${ }^{18)}$ Kinoshita J, Kimura Y, Matsumoto K (2003) compared the efficiency of air turbine, Carisolv and Er,Cr:YSGG Laser in removal of carious dentin and examined the morphological differences among these techniques under light microscopy and SEM. During caries removal, supplementary data was recorded concerning the clinical convenience of the three methods in terms of time, noise and difficulty in operation. The results showed that the carisolv group exhibited a very rough surface with thick smear layer, while Er,Cr:YSGG Laser group demonstrated smooth undulations with little 
smear layer and debris. They concluded that among the three methods, Er,Cr:YSGG Laser required the shortest time with no irritating noise. ${ }^{51)}$ Liu JF, Lai YL, Shu WY, Lee SY (2006) evaluated and compared the clinical efficiency and patient acceptance of Er:YAG Laser and conventional method during cavity preparation in permanent teeth. Results showed that $82.5 \%$ of children felt no pain at all when cavities were prepared with Laser. With the conventional mechanical preparation children showed more body and head movement. Although the Er:YAG Laser took about 2.35 times longer to prepare the same type of cavity, $92 \%$ of the children said that they would prefer Laser preparation for further caries therapy. It was concluded that cavity preparation with the Er:YAG Laser produces less pain and has acceptable efficiency compared to the conventional mechanical preparation. ${ }^{19)}$ Eren F, Altinok B, Ertugral F, Tanboga I (2013) evaluated and compared the pain perception, preparation time and patient perception during cavity preparation with conventional method and Er,Cr:YSGG Laser They showed that the perception of pain rated by the subjects was lower when the Laser technique was used. They also suggested that application of the Er,Cr:YSGG Laser system was a more comfortable alternative method to conventional mechanical cavity preparation. ${ }^{58)}$ These findings are similar to our study, in which $80 \%$ subjects found the procedure of caries removal with Laser to be more comfortable. However, some authors's findings were different. Hjertton PM, Bagesund M (2013) evaluated the effect on cavity preparation time, the pulse changes and the patient's subjective experience during removal of healthy tooth substance with high-speed bur and Er:YAG Laser. It was observed that Laser ablation caused unpleasant smell and longer cavity preparation time, but was preferred by a majority of the subjects. ${ }^{20)}$ Valerio RA et al (2016) evaluated the effectiveness and efficiency of an Er:YAG Laser for caries removal in primary molars, microbiological dentin analysis, and clinical restorations after 1 year. The efficiency of the treatments (the time necessary for the removal of carious tissue) was evaluated based on the time spent on caries removal in the deciduous molars. The efficacy (caries removal capacity) of the caries removal was determined by means of a blind test in which the examiner performed a tactile and visual examination of the dentin. They observed that Er:YAG Laser was less effective and had the same efficacy as bur preparation during caries removal at the pulpal wall of deciduous molars. In the surrounding walls, bur preparation was the more effective method. ${ }^{21)}$ Fornaini $\mathrm{C}$ et al (2012) evaluated the patient response to Er:YAG Laser when used for conservative dentistry. Before treatment, 100 patients were given a brochure that explained the relevant Laser-assisted dental procedures, and after dental treatment an 11-item questionnaire was administered to the patients to evaluate their satisfaction with the treatment. 89\% subjects chose Laser in the future, and $84 \%$ recommending it to family and friends. ${ }^{22}$

Caries detection dye was used after caries removal to check the efficacy of the method in the present study. Caries detector dyes are composed of two components including a dye and a solvent mostly made of propylene glycol. The dye in the caries detector bonds to the denatured collagen that is present in the outer infected dentin and not in the inner uninfected dentin and normal dentin therefore only the outer infected dentin is stained. ${ }^{23)}$ As a result, the product distinguishes between these two layers and enables the dentist to perform a conservative cavity preparation, removing only the outer infected dentin. It was seen that in both the groups caries detection dye was completely removed indicating that both the procedures were effective in caries removal.

In this study, majority of children showed positive behavioural response by following operator's instructions cooperatively and showed willingness to accept procedure in both the groups. Patient acceptance was higher when caries removal was done with Er,Cr:YSGG Laser group. Majority of children felt more pain after the procedure in Group B (Air-rotor handpiece group) than Group A (Er,Cr:YSGG Laser group) when evaluated through Wong Baker Pain rating Scale and Visual Analog Scale, and the difference was found to be statistically significant. Caries removal procedure in both the groups i.e. with Er,Cr:YSGG Laser and Air-rotor handpiece was equally efficacious. Although the time taken for caries removal with Er,Cr:YSGG Laser was much more than Air-rotor handpiece, the children found Er,Cr:YSGG Laser to be more comfortable. Hence Er,Cr:YSSGG Laser can be considered an effective clinical tool for caries removal in pediatric patients.

\section{Conclusion}

Children experienced less pain during the caries removal procedure with Laser than with Air-Rotor handpiece. Mean time taken for caries removal was more using Laser than Air-Rotor handpiece, however, Er,Cr:YSGG Laser and Air-rotor handpiece were equally efficacious for caries removal. Most of the of children found the procedure of caries removal with Er,Cr:YSGG Laser to be more comfortable on verbal response.

Within the parameters and limitations of the present study, it is suggested that Er,Cr:YSGG Laser seems to be an acceptable tool for caries removal in primary teeth. Children found caries removal with Er,Cr:YSGG Laser to be more comfortable even though time taken was more than the conventional method using Air-rotor handpiece.

\section{Limitations}

This study was performed on a small sample size howev- 
er further studies need to be done on a larger sample size and in different age groups. Also, this study was done on children with Frankl 3 and 4 rating, i.e., positive

\section{References}

1: Musale PK, Mhatreb S. Laser Assisted Caries Removal: A Boon in Pediatric Dentistry. J Laser Dent. 2011;5(2):29-32.

2: Banerjee A, WatsonTF, Kidd E. Consevative dentistry: Dentin caries excavation: a review of current clinical techniques. British Dental Journal. 2000;188(9):476-482.

3: Ana PA, Bachmann L, Zezell DM.Laser effects on enamel for caries prevention.Laser phys 2006;16(5):865-75.

4: Martens LC. Laser-assisted pediatric dentistry: review and Outlook. Journal of Oral Laser Application. 2003; 4: 203209. 8. Visuri SR, Walsh JT, Wigdor HA. Erbium Laser ablation of dental hard tissue: effect of water cooling. Lasers in Surgery and Medicine. 1996; 18: 294-300.

5: Musale PK, Mhatreb S. Laser Assisted Caries Removal : A Boon in Pediatric Dentistry. J Laser Dent. 2011;5(2):29-32.

6: Olivi G, Genovese MD. Laser restorative dentistry in children and adolescents. Eur Arch Paediatr Dent 2011; 12(2):68-78.

7: Eren F, Altinok B, Ertugral F, Tanboga I. The effect of erbium, chromium:yttrium-scandium-gallium-garnet (Er,Cr:YSGG) Laser therapy on pain during cavity preparation in paediatric dental patients: a pilot study. Oral Health Dent Manag. 2013;12(2):80-4.

8: Yasin OM. in vitro studies of the effect of a dental explorer on the formation of an artificial carious lesion. ASDC J Dent Child 1995;62:111-7

9: Anttonen V, Seppa L, Hausen H. Clinical study of the use of the LASER fluorescence device Diagnodent for detection of occlusal caries in children. Caries Res 2003;37:17-23.

10: Bengtson AL, Gomes AC, Mendes FM, Cichello LR, Bengtson NG, Pinheiro SL. Influence of examiners clinical experience in detecting occlusal caries lesions in primary teeth. Pediatr Dent 2005;27:238-43.

11: De Paula AB, Campos JA, Diniz MB, Hebling J, Rodrigues JA. In situ and in vitro comparison of LASER fluorescence with visual inspection in detecting occlusal caries lesions. LASERS Med Sci. 2011;26(1):1-5.

12: De Benedetto MS, Morais CC, Novaes TF, de Almeida Rodrigues J, Braga MM, Mendes FM. Comparing the reliability and definitely positive children. So further studies can be done including children with Frankl 1 and 2 rating, i.e., definitely negative and negative children.

of a new fluorescence camera with conventional LASER fluorescence devices in detecting caries lesions in occlusal and smooth surfaces of primary teeth. LASERS Med Sci. 2011;26(2):157-62.

13: Bader JD, Shugars DA. A systematic review of the performance of a LASER fluorescence device for detecting caries. J Am Dent Assoc. 2004;135(10):1413-26.

14: Magaret ND, Clark TA, Warden CR, Magnusson AR, Hedges JR. Patient satisfaction in the emergency department--a survey of pediatric patients and their parents. Acad Emerg Med. $2002 ; 9(12): 1379-88$.

15: Newman CJ et al. A comparison of pain scales in Thai children. Arch Dis Child. 2005 Mar;90(3):269-70.

16: Boj J, Galofre N, Espana A, Espasa E. Pain perception in pediatric patients undergoing

LASER treatments. J Oral LASER Applications. 2005; 5(2): 859.

17: Rathnam A, Madan N, Madan N. The language of pain: A short study. Contemp Clin Dent. 2010 Jul;1(3):142-5.

18: Mtsumoto K, Hossain M, Hossain MM, Kawano H, Kimura Y. Clinical Assessment of Er,Cr:YSGG LASER Application for Cavity Preparation. Journal of Clinical LASER Medicine and Surgery. 2002;20(1):91-96.

19: Liu JF, Lai YL, Shu WY, Lee SY. Acceptance and Efficiency of Er:YAG LASER for Cavity Preparation in Children. Photomedicine and LASER Surgery. 2006;24(4):489-493.

20: Hjertton PM, Bagesund M. Er:YAG Laser or high-speed bur for cavity preparation in adolescents. Acta Odontol Scand. 2013 ;71(3-4):610-5.

21: Valerio et al. Caries removal in deciduous teeth using an Er:YAG Laser: randomized split-mouth clinical trial. Clin Oral Investig. 2016;20(1):65-73.

22: Fornaini C, Riceputi D, Lupi-Pegurier L, Rocca JP. Patient responses to Er:YAG Laser when used for conservative dentistry. Lasers Med Sci. 2012 Nov;27(6):1143-9.

23: Hosoya Y, Taguchi T, Tay FR. Evaluation of a new caries detecting dye for primary and permanent carious dentin. J Dent 2007 Feb;35(2):137-43. 